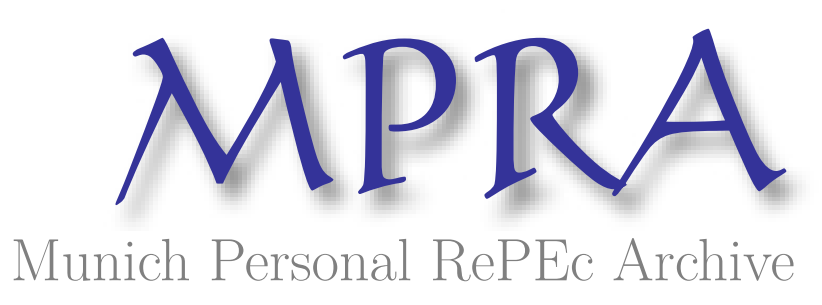

\title{
Economics Research in France: Tentative Conclusions Based on EconLit Database
}

\author{
MIRUCKI, Jean \\ University of Valenciennes (UVHC) France
}

September 1999

Online at https://mpra.ub.uni-muenchen.de/27431/

MPRA Paper No. 27431, posted 23 Dec 2010 07:32 UTC 


\title{
Economics Research in France: Tentative Conclusions Based on EconLit Database
}

\author{
Jean Mirucki \\ Université de Valenciennes, France
}

\begin{abstract}
Despite France's influential role in and significant impact on the development of economic thought in the past, it seems that no recent publication has assembled an up-to-date inventory of its internationally best known contemporary economists. The purpose of this study, therefore, is to produce an exploratory survey for 1998 of the scientific contributions of representative economics research groups in France based on the EconLit bibliographic database. Three indicators, one relating to overall visibility, one to net production and one to international presence, have been used to evaluate and compare two major categories of representative groups: the "French specificity" category [including Conseil National des Universités (CNU) and agrégation groups] and another made up of more "traditional" groups (including editorial committees of journals and the chairmen and management committee of a national association of economists). The results indicate a clear dichotomy between the two. Moreover, the poor performance of the first of the above categories measured by all three indicators raises serious questions about the way the public university system operates in France and the future implications thereof in the light of the globalisation of the production and dissemination of scientific knowledge.
\end{abstract}

\section{INTRODUCTION}

For several decades many studies on the evaluation of original scientific contributions, including those of Bairam (1994), Colander (1989), Conroy et al. (1995), Laband and Piette (1994), and Nederhof and Wijk (1999), have served to classify individuals, institutions and journals. These studies, covering several disciplines and published mainly in English-language journals, have not been so popular in France, which is regrettable for several reasons. For a start, the lack of this kind of information is a drawback for young researchers, both those seeking benchmarks and others more concerned with assuming important administrative tasks not 
directly connected with their research work. Secondly, all the comparative studies carried out on either an individual or an institutional basis that are published and discussed abroad almost invariably ignore the existence of the French-speaking world. Hence this exploratory survey, which some may consider inopportune, aims to fill this gap, while in addition yielding some surprising and encouraging results, which are useful for all French economists.

The purpose of our survey is to draw some tentative conclusions regarding the scientific contributions of representative economic research groups in France using the EconLit bibliographic database. The advantage of this approach is that it will enable us to evaluate the position of these representative groups in relation to each other, using three simple criteria to measure scientific activity and its dissemination among the international community.

Our overall visibility indicator, which measures the number of entries in EconLit, shows how frequently a researcher's name appears in the database. The degree of contact maintained in this way with other researchers is a precondition of any claim to notoriety. This is a purely quantitative dimension, which totals the number of times a name appears either directly, indirectly or implicitly. Direct appearances concern statements signed by the author; indirect appearances are taken to be the analyses, commentaries or citations concerning his work made by others; while implicit overall visibility is the case where the person's name is used as a reference to illustrate a model, a concept or other theoretical development. Regardless of the wealth of contributions or achievements which a particular scientist may lay claim to, if he does not tangibly exist in the eyes of other researchers using the database, either through his statements, or by the attention others might give him, then he may well never appear in any later citations, and therefore never be able to build up his notoriety, regardless of how justified his claims may be.

Net production is the second indicator we need to measure the truly scientific dimension of a researcher. It adopts the rules applied in the specialised literature by considering only articles selected by the anonymous arbitration procedure and is calculated in proportion to the author's effective contribution. Excluded from consideration are: books, collective works, book reviews, theses, discussion records, special issues, proceedings of meetings, commentaries, replies, corrections, regular features, chronicles, official speeches, commissioned articles, presentations, editorial notes, etc. This rather strict approach, which is debatable rather than disputable, may well not meet with approval in France, whereas it is the scientific standard recognised throughout top Englishlanguage literature. The underlying theory is that the progress of research should be measured by the addition to universal knowledge made by original contributions, and that only an appreciation of works chosen by the impartial judgement of peers (whence the anonymity rule) can best ensure the highest 86 possible quality in the dissemination of new knowledge. The publication 
system that best fulfils these conditions is that of scientific journals, with reading committees that apply the anonymous arbitration procedure for unsolicited articles. It is in this light that Gans and Shepherd (1994) explain how particular articles come to be rejected, including some submitted by Nobel Prize winners. Beyond that basic consideration, Laband (1990) reminds us of the clear difference from the point of view of impact, in terms of citations and hence of potential notoriety, between journal articles and books. According to him, the latter, even published by the best English-speaking publishers, make up only a very small fraction of the citation potential of a single article and for a distinctly more limited lifetime.

International presence is the last of our three indicators, particularly suited to a community of non-English-speaking researchers. It replaces, in a way, the very demanding classifications of English-language surveys established on the basis of very restricted lists of the best journals in the world, which boil down in fact to exclusively English-language journals for any selected list of less than twenty. In rejecting this criterion in our own survey, and instead extending our interpretation of international presence to some 600 foreign journals, we have avoided a process of excessively drastic elimination, which few individuals, and especially representative French groups, would have survived. The only special condition which we have applied, for purely practical reasons, is that we have tried to overcome the language barrier by selecting, for net production, only articles published in English in Englishlanguage or multilingual journals, with a view to guaranteeing "language visibility". This is because, to the extent that a researcher wishes to be recognised for his original work and to be appreciated by as many colleagues as possible worldwide, he will be able to enhance his citation potential by publishing, say, an article in Kyklos in English, rather than in French or German.

To the extent that notoriety constitutes the ultimate objective for a researcher or a group of scientists, and that it represents a sufficient criterion of successful research, why concentrate only on the three indicators described above and not go on to consider this other aspect? In fact, appreciating the degree of notoriety achieved by an individual's entire work implies a qualitative dimension, which may be controversial in a number of ways. Of all the possible methods of measurement, the number of citations reckoned on the basis of the publications given in the Social Science Citation Index is undoubtedly the method most used in available studies. ${ }^{1}$ Since the work in hand is essentially exploratory and aimed at drawing only preliminary conclusions on a new and sensitive subject, it seemed more constructive to look at France's real visibility abroad through some of its most representative groups, to highlight the contrasts between different traditional research structures and to give our own statistical interpretation, as our contribution to a debate initiated a few years ago by Laffont (1995), in the knowledge that scientific evaluation by citation is already part of our next stage. 


\section{CHOICE OF REPRESENTATIVE GROUPS}

Considering what is nationally and internationally at stake in scientific research, with the growing globalisation of knowledge production and the proliferation of new information and communication technologies, both researchers and the public authorities need to take stock of where they stand and how well they are doing in relation to the rest of the world. ${ }^{2}$ An exploratory survey must therefore be undertaken as a means of identifying shortcomings, advantages and possibilities as soon as possible, and if necessary taking appropriate action. We shall start by examining the functioning of two university systems, which apply different principles in order effectively to achieve the objectives of scientific notoriety in the general interest of society as a whole.

In the American system, where the university is considered as the real engine of scientific knowledge production, an academic's tenure represents a long-term investment for the institution, as explained by Goodwin and Sauer (1994) and by McPherson and Schapiro (1999), and will only be granted against the assurance of high quality, confirmed productivity, backed up by a portfolio of publications built up over a trial period of several years. The so-called "up or out" rule (i.e. promotion or exclusion) ensures that the system's inherent principle is preserved, since the investment in human capital is decided solely in the light of objectives achieved over a medium-term probationary period, with the certainty that no working teacher/researcher is exempt.

In France, higher education and research are divided between the private sector and the public sector, the latter being subject to specific rules regarding the recruitment and subsequent careers of its teachers/researchers. Lecturers are taken on for a probationary period, lasting at most two years, after which full appointment will normally follow automatically in the light of an appreciation of the teaching activities and the pedagogic or administrative duties performed by the probationer during this period at the institution. Thus young academics are recruited on the basis of their research portfolio, made up of their thesis, any related publications and any other works produced. They will not, however, be reassessed formally prior to their final appointment. The Conseil National des Universités (CNU) becomes involved in the recruitment and advancement process and, in certain cases, the promotion of candidates to a professorship, but not in their initial appointment. This means that their whole career could take place without any obligation whatever to produce new publications, since a steady improvement in their financial situation, in addition to job security, will be guaranteed by their step-by-step progression up the professional scale.

In the case of the agrégation competitive examination, which opens the door to the higher ranks of professorship, the matter of appointment is even more straight88 forward, since the probationary period is done away with altogether. Recruitment in 
that case is immediate and definitive, as admission is based on past research work and on lessons in which candidates can display their level of knowledge ${ }^{3}$ as well as their teaching abilities. The system was conceived in the 19th century as a way of selecting the most promising young teachers for secondary school and was later applied to higher education, ${ }^{4}$ the logic behind the system being at present to take account of candidates' abilities both as teachers and researchers. However, considering that poor teaching performance during examination hearings is not penalised in any way and that already established teachers do not have to undergo that type of assessment test, the system no longer fully guarantees a high quality of teaching. On the other hand, the recognition of a candidate's very high quality of research in the initial stages of the competitive exam may be lost in the case where a promising researcher is unlucky in the subsequent lessons draw. ${ }^{5}$ This means that the examination inherently no longer ensures the primacy of research ${ }^{6}$ and may even detract from it as a result of the random choice of lesson subjects.

The evaluation of economics research in France must then distinguish between "French specificity" (made up of CNU and agrégation groups ${ }^{7}$ ), and other selective groups measured by more "traditional" notoriety criteria, in line with common evaluation practices applied in most other countries, and compare the results.

\section{French specificity: $\mathrm{CNU}$ and higher education agrégation examination}

\section{Lecturers (maîtres de conférences) and CNU professors}

The CNU is made up of lecturers (maittres de conférences, MCF) and professors (PR) elected by their peers or appointed by the public authorities. Their numbers are not the same and vary from one period to another. Only the last three bureaux, of 1988, 1992 and 1995, have been included, with a distinction being drawn between lecturers and professors, though none between appointees and elected staff, although such a distinction would have been possible.

\section{Presidents and members of the Jury and candidates who have passed the agrégation examination in higher education}

It may be remembered, as we said earlier, that the specific method of recruitment and career development in France are such that selected candidates do not have to undergo a probation period to confirm their research productivity. The outcome depends in fact solely on the sovereign judgement of the agrégation examination Jury. ${ }^{8}$ It would therefore be useful initially to measure the three indicators for candidates who passed the examination, with a view to assessing their overall visibility, their net production and their international presence at the start of their careers. In order to follow the fair assessment principle applied in the French civil service, that is, whereby an assessment should be "based on the judgement of 
peers holding a rank at least equal to or higher than that of the candidate", the analysis will also be applied to the members of each of these Juries and, $a$ fortiori, to their Presidents.

The 30 candidates who passed the last three examinations of 1994, 1996 and 1998 will be considered, together with the seven members of each Jury. A fourth series of 16 candidates who passed the second examination of 1998 will then be added with that Jury. For the Jury presidents (first and second examinations), the series has been extended to the seven examinations covering the period from 1989 to 1998 .

\section{Other selective groups: the traditional references of scientific notoriety}

\section{Typically national references}

In a more "traditional" approach, the selected reference groups concern the editorial committees of two major non-specialised journals and one national association of economists. The choice of the two journals, the Revue d'économie politique and the Revue économique, is of course arbitrary and therefore open to criticism, especially since other journals would have been just as suitable. Considering the exploratory nature of this survey, however, it is quite conceivable that in the near future the selection may be extended to a broader panel of either non-specialised or specialised journals, whether French, French-language or bilingual. The composition of the French-speaking membership of the journal editorial committees of 1998 has been kept, as for the members of the management committee of the Association Française de Science Économique (AFSE). The 11 former AFSE presidents have been assessed on their contributions on the date they took office, which meant starting the series no further back than 1978, considering that the EconLit database began only in 1969. Insofar as membership of the Conseil d'Analyse Économique (CAE) implies considerable influence over the economic affairs of the State, this Council also deserved detailed analysis on the basis of its official 1997 composition. Only the 30 French members of the CAE were selected for specific assessment.

\section{French-speakers on the international scene}

For the general public, supreme notoriety for economists goes with the award of the Nobel Prize. In fact, as Mirucki (1986) has noted, the progression towards this often belated recognition may well be "heralded" by earlier appointments or nominations. The two most important promotions are nomination to the Fellows of the Econometrics Society, the first step towards high-level international recognition, which may be followed a few years later in the case of the chosen few by the title of Foreign Honorary Member of the American Economic Association. In this survey,

90 two reference groups have been evaluated: firstly the 27 French-speakers admitted 
as Fellows of the Econometrics Society since 1973, and secondly, all the Foreign Honorary Members of the American Economic Association received since 1975 out of the previous group, plus the only French Nobel Prize for Economics. ${ }^{9}$ The six Honorary Members will therefore make up the majority of the EconLit $100+$ group described in the following paragraph.

In fact, departing from the approach we have followed so far, which consists in appreciating the position held by certain formal groups among the most representative of economic research in France, it seemed worth making up a new informal group, called "EconLit $100+$ ", based on the first proposed evaluation criterion. By identifying French-speakers with an overall visibility higher than a hundred in the EconLit reference database, we can then estimate the highest levels achieved by French-speaking researchers. Among the ten members ${ }^{10}$ of the EconLit 100 + group, we find eight members of the Fellows of the Econometrics Society, who include all six of the above-mentioned Foreign Honorary Members of the American Economic Association.

\section{RESULTS AND IMPLICATIONS: TENTATIVE CONCLUSIONS}

An unmistakable dichotomy emerges from Table 1. Out of the fourteen groups considered, the averages of the first half related to "French specificity" (CNU and agrégation) lie distinctly below those of the other selective groups of French-speaking researchers. For the latter, the overall visibility indicator is ten times higher; the net production indicator is roughly six times higher, while the international presence indicator, the most significant of the three, is 14 times greater than for the CNU + agrégation groups.

The international impact of articles concerns only a fifth of publications in the first part (19\%) but almost half in the second ( $47 \%)$. The classifications of the three indicators confirm without a single exception the clear dichotomy between the two parts.

A more detailed analysis, using a series of graphs ${ }^{11}$ shows the profiles of each group, though it should be borne in mind that results obtained only from regression tests will supply information on the "positioning" of variables and not on the distribution of publication frequencies.

\section{CNU + agrégation groups: "French specificity"}

\section{CNU lecturers}

The data are related to the last three groups made up in 1988, 1992 and 1995. They show that half the lecturers have no entries in EconLit, and therefore no corresponding net production, while for the 44 members as a whole, only five have published in foreign journals. Thanks to the good performance of the leading bureau member in 1992, who has since been promoted to the position of Director 
Table 1. Overall visibility, net production and international presence of representative economic research groups in France (averages)*

\begin{tabular}{|c|c|c|c|c|c|c|c|c|}
\hline OV & Rl & $\begin{array}{l}\text { Representative groups of French } \\
\text { researchers }\end{array}$ & Year & NP & $\mathrm{R} 2$ & IP & R3 & $\mathrm{IP} \%$ \\
\hline 0.9 & & CNU: MCF & 1988 & 0.9 & & 0.0 & & 0 \\
\hline 2.1 & & CNU: MCF & 1992 & 1.3 & & 0.3 & & 23 \\
\hline 0.8 & & CNU: MCF & 1995 & 0.6 & & 0.1 & & 17 \\
\hline 1.6 & 13 & Averages for CNU (MCF) (Lecturers) & $88-95$ & 1.1 & 13 & 0.2 & 13 & 18 \\
\hline 4.1 & & CNU: PR & 1988 & 3.0 & & 0.4 & & 13 \\
\hline 13.3 & & CNU: PR & 1992 & 5.4 & & 0.8 & & 15 \\
\hline 9.1 & & CNU: PR & 1995 & 4.5 & & 0.6 & & 13 \\
\hline 9.4 & 9 & Averages for CNU (PR) (Professors) & $88-95$ & 4.5 & 9 & 0.6 & 10 & 13 \\
\hline 10.3 & & Agrégation Jury & 1994 & 5.7 & & 0.7 & & 12 \\
\hline 10.0 & & Agrégation Jury & 1996 & 4.0 & & 1.3 & & 33 \\
\hline 8.4 & & Agrégation Jury & 1998 & 5.7 & & 1.0 & & 18 \\
\hline 9.6 & 8 & Averages for agrégation Jury: First exam & $94-98$ & 5.1 & 8 & 1.0 & 9 & 19 \\
\hline 5.0 & 10 & Agrégation Jury: Second exam & 1998 & 3.6 & 11 & 1.2 & 8 & 33 \\
\hline 4.9 & 11 & Agrégation Jury Presidents & $89-98$ & 3.8 & 10 & 0.4 & 12 & 11 \\
\hline 3.0 & & Passed agrégation & 1994 & 1.9 & & 0.4 & & 19 \\
\hline 3.1 & & Passed agrégation & 1996 & 1.7 & & 0.5 & & 31 \\
\hline 3.2 & & Passed agrégation & 1998 & 2.0 & & 0.6 & & 30 \\
\hline 3.1 & 12 & Averages for Passed agrégation: First exam & $94-98$ & 1.9 & 12 & 0.5 & 11 & 27 \\
\hline 1.0 & 14 & Passed agrégation: Second exam & 1998 & 1.0 & 14 & 0.2 & 13 & 20 \\
\hline 4.8 & & Averages for $\mathrm{CNU}+$ agrégation groups & & 2.6 & & 0.5 & & 19 \\
\hline 19.4 & 7 & Revue Économique & 1998 & 10.3 & 6 & 1.3 & 7 & 12 \\
\hline 44.1 & 3 & Revue d' Économie Politique & 1998 & 13.4 & 4 & 5.3 & 3 & 39 \\
\hline 27.4 & 6 & AFSE Directing Committee & 1998 & 9.4 & 7 & 3.6 & 5 & 38 \\
\hline 27.6 & 5 & AFSE Presidents & $78-98$ & 14.1 & 3 & 3.1 & 6 & 22 \\
\hline 37.1 & 4 & $\begin{array}{l}\text { Conseil d'analyse économique } \\
\text { (French-speakers) }\end{array}$ & 1997 & 12.2 & 5 & 5.2 & 4 & 42 \\
\hline 77.1 & 2 & $\begin{array}{l}\text { Fellows of the Econometrics Society } \\
\text { (French-speakers) }\end{array}$ & $73-98$ & 22.8 & 2 & 15.9 & 2 & 70 \\
\hline 168.4 & 1 & EconLit 100 + (French-speakers) & 1998 & 39.3 & 1 & 23.9 & 1 & 61 \\
\hline 47.8 & & $\begin{array}{l}\text { Averages for selective groups } \\
\text { of French researchers }\end{array}$ & & 15.3 & & 7.2 & & 47 \\
\hline
\end{tabular}

$\begin{array}{ll}* & \text { Abbreviated column headings. } \\ \text { OV } & \text { Overall visibility indicator: number of times the name is found (with rating R1). }\end{array}$

NP Net production indicator: restricted to number of journal articles subject to anonymous arbitration procedure (excluding books, collective works, book reviews, theses, discussion records, special issues, minutes of meetings, commentaries, replies, corrections, regular features, chronicles, official speeches, commissioned articles, presentations, editorial notes, etc.) and adjusted for effective contribution share in the case of multipleauthor articles (with rating R2).

IP International presence indicator: net production, restricted to articles published in English in Englishlanguage or multilingual journals, showing language visibility abroad (with rating R3).

IP\% International presence coefficient: international impact of net production (IP/NP ratio).

Source: EconLit 1969-3/1998, database of the American Economic Association. 
of Research at the CNRS and appointed member of the Fellows of the Econometrics Society, overall visibility and net production improved substantially in 1992 but remained generally flat in 1995.

\section{CNU professors}

The data on professors show a distinct improvement compared with previous groups, while maintaining the same characteristics, i.e. definite progress in 1992 and similar profiles for 1992 and 1995. This time, only three members in 1988 and two in 1995 have no entries in EconLit, while a little less than half the members in each of the series has published abroad. Overall visibility is six times greater among professors than among lecturers, but the ratio is only three times more for the international presence indicator. In practical terms, only one-third of the professors would have published the equivalent of a whole article in a foreign journal by the date they were elected or appointed to the $\mathrm{CNU}$.

\section{Members of the agrégation examination jury}

The analysis of Jury members covers the three first examinations of 1994, 1996 and 1998, to which has been added the second examination of 1998. Apart from the very first observations, overall visibility is below that of the CNU professors. With a very uneven distribution, the 1996 Jury includes the two best performances as well as the two poorest, i.e. two members with no entry at all in EconLit. For net production, the four series come closer at each observation level, although the performance on the whole remains rather modest. It is quite surprising to note that at least three Jury members of the First examination, in each series, had no international presence. Generally speaking, the Second examination Jury behaves in a similar way to the other three, despite poorer net production to start with.

\section{Agrégation examination jury presidents}

The three indicators may be evaluated from the data concerning presidents of each first and second agrégation examination over the last ten years. Overall visibility and net production are generally very close, while international presence is nonexistent for most of them. In fact, despite their dominant hierarchical position, ${ }^{12}$ five out of seven have never published an article in a foreign scientific journal covered by EconLit ${ }^{13}$ throughout their careers.

\section{Candidates passing the agrégation examination}

The 30 successful candidates at each first agrégation examination in 1994, 1996 and 1998 are very similar as far as overall visibility is concerned, with between three and six absent from EconLit. This indicator is much better than that of the second 
1998 examination, for which nearly half are absent. There is a fall-off in net production, but less so than in the case of Jury members. International presence is fairly similar to that of CNU professors, bearing in mind that some are starting their careers while the others have already reached a mature stage. Among the successful candidates, only one-third in 1994, half in 1996 and a little more than a quarter in 1998 and one-fifth in the second 1998 examination have published in scientific journals abroad. Despite the prestige attached to the ranking of successful candidates, only one of the four candidates who came first in each of the examinations had succeeded in publishing a single article abroad, and then only on a joint basis, by the date of the examination.

\section{Other selective groups: the traditional references of scientific notoriety}

For the purposes of the analysis, a distinction was drawn between two groups: national references, i.e. the two major non-specialised journals plus the Association Française de Science Économique (AFSE), and secondly the performance of Frenchspeakers among the international community, i.e. members of the Fellows of the Econometrics Society and Foreign Honorary Members of the American Economic Association, the latter all appearing in EconLit $100+$. For the purpose of comparing with the second group, the analysis also includes members of the Conseil d'analyse économique, reflecting a political choice at top government level, and Jury presidents of the agrégation examination, who, in the spirit of "French specificity", officially represent the top crust of university research in economics.

\section{National selective groups}

In Figure 1, overall visibility for the four selective typically national reference groups shows distinctly higher averages than in all the previous cases, judging by the very first observations, and despite two absences in EconLit for two of the series. It should be pointed out that some researchers as a result of the notoriety gained may have appeared in more series than one, which may have increased the averages. Thus, contrary to the figures given in Table 1, the difference of profile between the editorial committees of the two journals, to a great extent, is relatively less apparent. Apart from the first three observations, the lesser performance of the AFSE presidents may come as a surprise. Net production brings the two journals even closer together, both of these being caught up by the members of the AFSE management committee. Where international presence is concerned, we find a significant number of absences: about a third as many for the AFSE management committee as for the Revue d'Économie Politique, and over half of the Revue Économique.

\section{Selective groups of French-speakers in the International arena}

In the second category of selective French-speaking groups, Figure 2, com94 pared with Figure 1, shows the highest number of EconLit entries observed so far. 
Figure 1. Global visibility of presidents and directors of the AFSE, and editors of selected journals

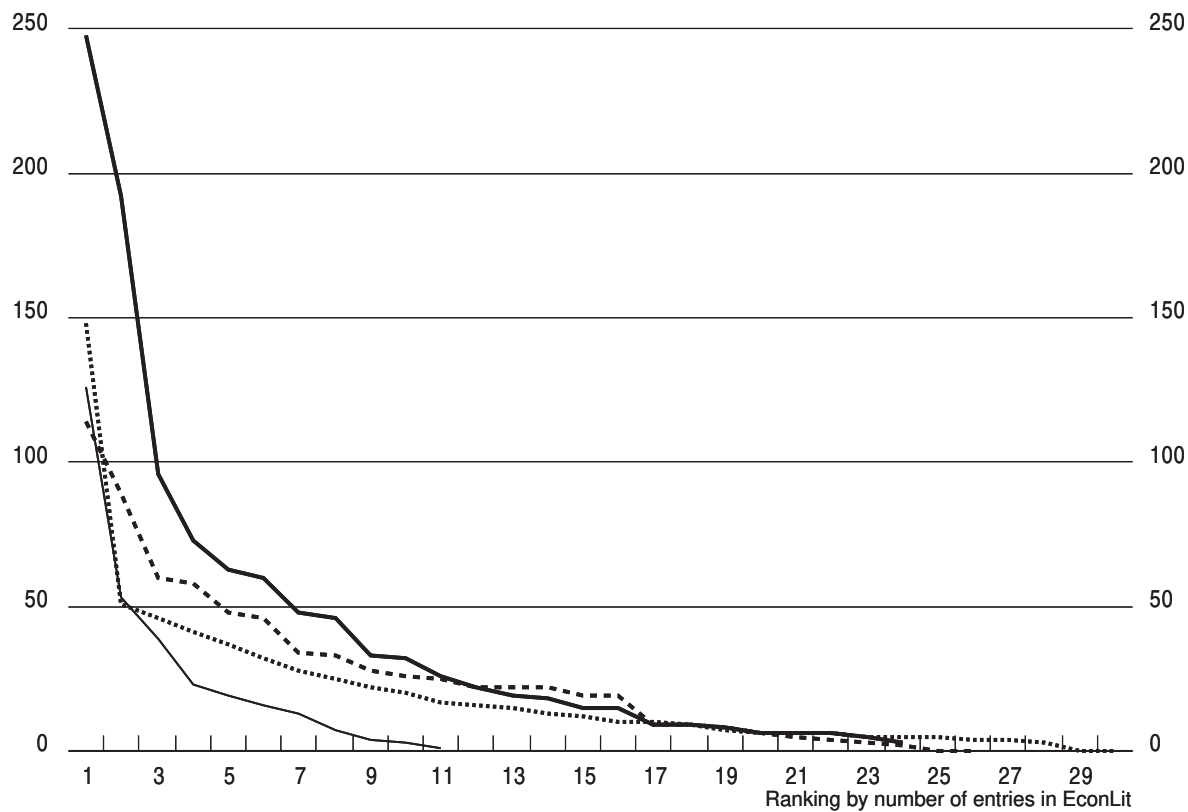

Some double and even triple appearances among the series, especially the upper half of the first ten observations, would imply that only about $80 \%$ out of the total of 74 representations can be taken as the real number of different researchers identified in Figure 2. One quarter of the CAE members and one agrégation Jury president have no entry in EconLit. The distinct contrast between Jury presidents and the other three groups sheds a very revealing light on the position held by the top level of "French specificity" within the circle of French-speaking researchers when it comes to their presence in an international showcase such as the EconLit database. Net production roughly follows the same profiles as before, with for the EconLit 100 + group a declining tendency for the second half. 
Figure 2. Global visibility of selective groups of francophones

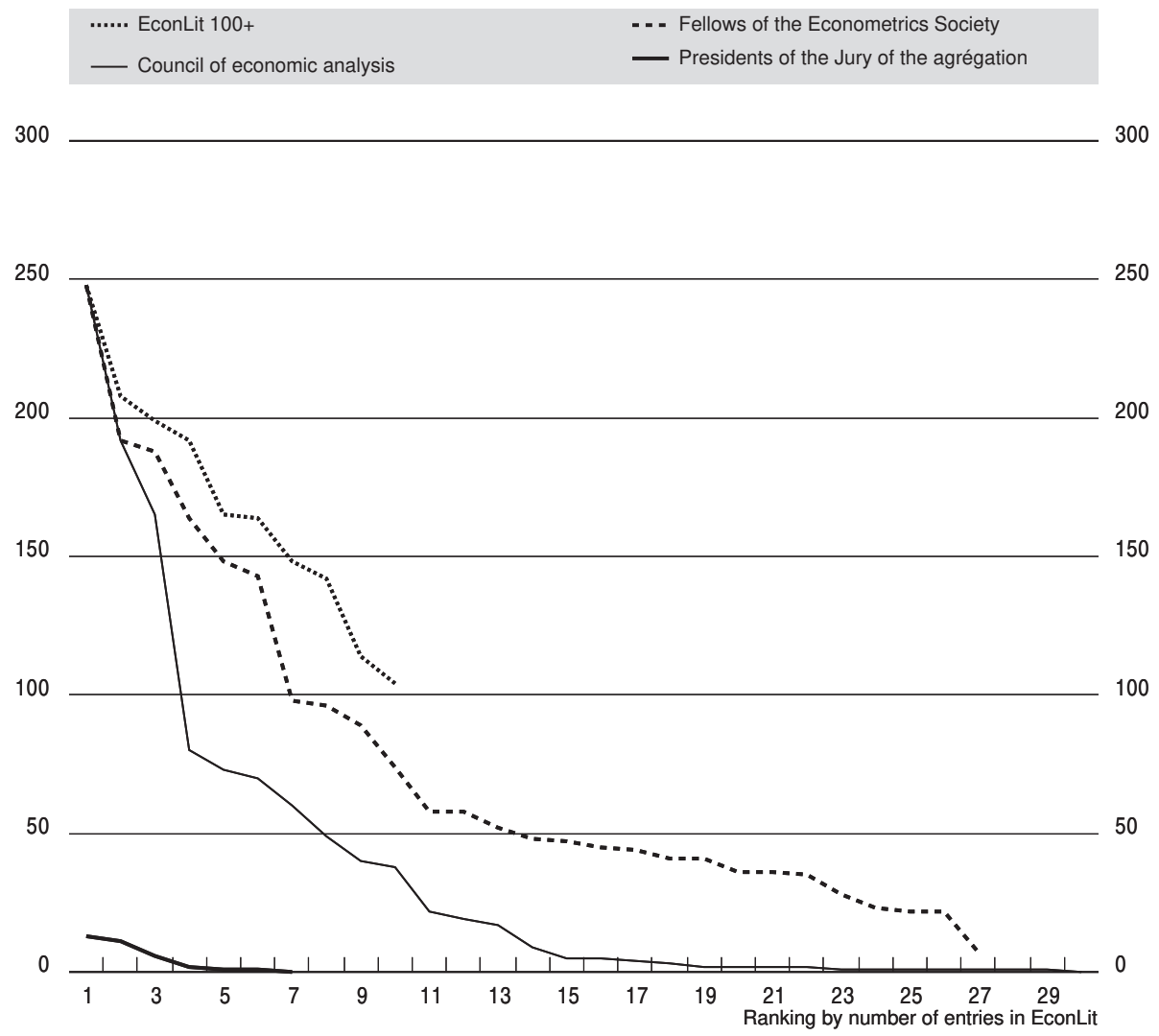

A new ranking appears in Figure 3, reflecting the international presence of French-speakers. Once again, it is worth sounding a word of caution against any primary interpretation of the averages given in Table 1. At the top come the first five observations, related to researchers of the EconLit $100+$ group and to the group of the Fellows of the Econometric Society (these are duplicates), the first three being at the same time Foreign Honorary Members of the American Economic Association. The second rank is held by the rest of the members of the Fellows of the Econometrics Society, followed by the other part of the EconLit $100+$ group, ahead of a good top half of CAE members. In terms of international presence, the contrast observed in Figure 3 between agrégation Jury presidents and the other three groups 96 is quite striking and not a little surprising. 
Figure 3. International presence of selective groups of francophones

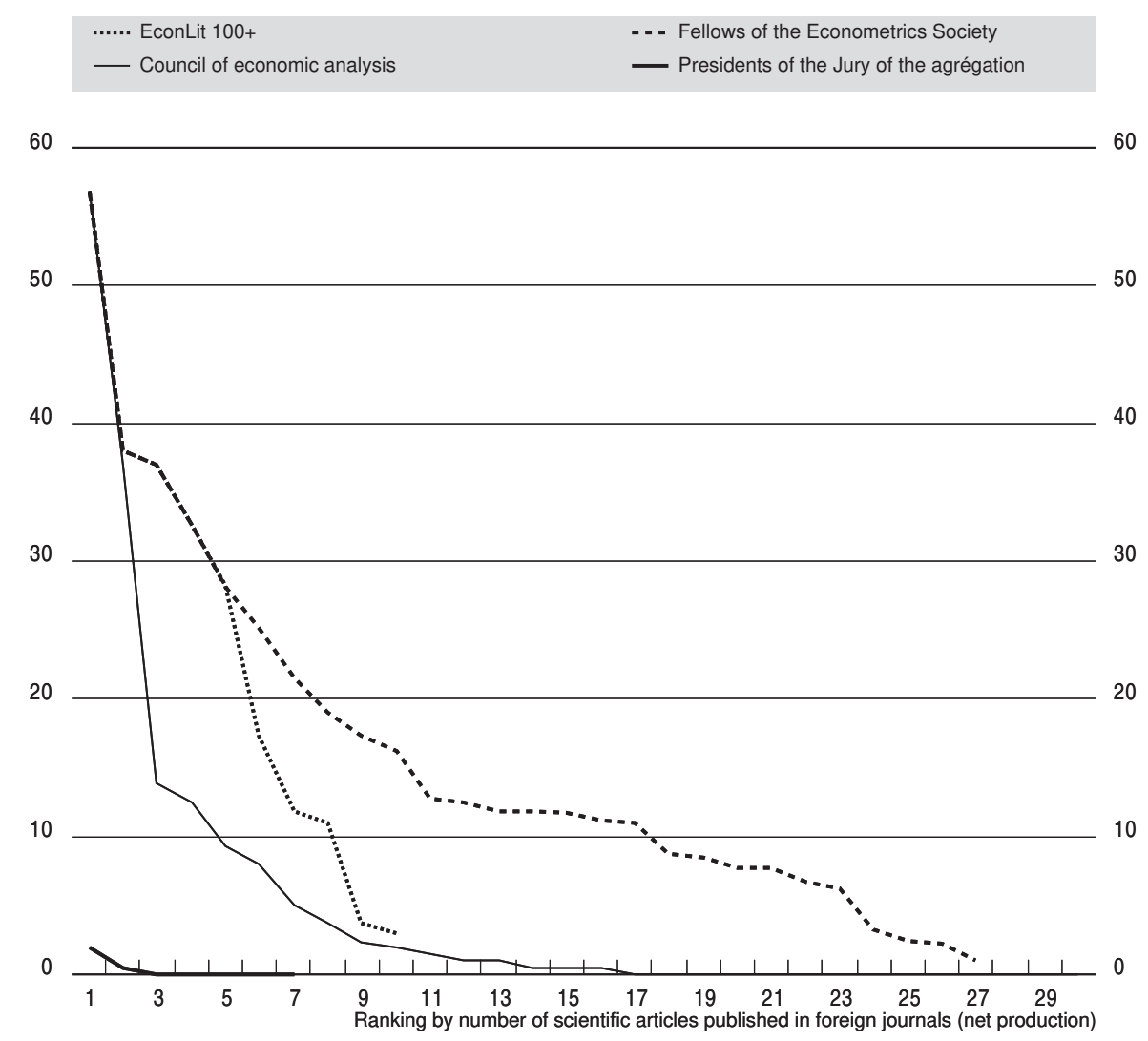

\section{TENTATIVE CONCLUSION}

This exploratory analysis carried out with the help of the EconLit bibliographical database constitutes a mere overview of descriptive statistics. It can be performed by any researcher using or having access to a recent version of this database available in the form of a CD-ROM. This means that potentially several thousand economists can lay their hands on the necessary data, a process which is bound to become easier still in the future, since EconLit may also be accessed on the Internet. In addition, comparative analyses with other countries or language groups can now 
be made concerning the groups of researchers applying the traditional standards of notoriety, included in the second part of Table 1.

The purpose of this study was to check whether the criteria for evaluating research in France were the same as those applied in the international scientific community at large or might be even partially related. The results in effect show an undeniable dichotomy between the two categories of groups. First we have the circle of public higher education, with its "French specificity" embodied in its recruitment and career advancement rules, a set of procedures and practices governed by the members of the $\mathrm{CNU}$ and those of the agrégation Jury, with the backing of the public authorities. In the light of information published on other countries, the figures obtained are disappointing and somewhat alarming.

This pessimistic view disappears rapidly if we examine the second category of the more "traditional" groups, made up mainly, as in most of the industrialised countries, on the basis of performance and the degree of notoriety acquired according to the rules of competitive publication. This category includes a number of academics and reflects a fairly decentralised geographical distribution. The best performances come from groups which have already obtained recognition abroad, i.e. the Frenchspeaking members of the Fellows of the Econometrics Society and the EconLit 100 + group, most of the latter being also Foreign Honorary Members of the American Economic Association. This means that a great many of these researchers make a quite commendable contribution to France's presence on the international scene, going against any preconceived ideas regarding the domination of English-speaking economists or the impermeability of their journals to European work.

Admission to the very select group of Foreign Honorary Members of the American Economic Association is considered as a very promising step forward towards the waiting room for potential Nobel Prize laureates, considering that all non-American recipients of the prize ${ }^{14}$ first went through the stage of being admitted Honorary Members. Hence it is encouraging to note that, in the various classifications drawn up in another study prepared by Mirucki (19996), which concentrated specifically on the 52 Foreign Honorary Members of the American Economic Association (Englishspeakers who are either non-American or nationals of other countries in the world), the one who comes out top is always a Frenchman, a provincial academic, ${ }^{15}$ the same person we find at the top of the lists in Figures 2 and 3 of selective Frenchspeaking groups according to criteria of overall visibility or international presence.

\section{Acknowledgement}

The author wishes to thank more specifically Drucilla Ekwurzel and Jean-Jacques Laffont for their encouragement and their commentary. 


\section{Notes}

1. See Davis and Papanek (1984), Downing and Stafford (1981), Laband (1990), Laband and Piette (1994), Liebowitz and Palmer (1984) and Wouters (1999).

2. Another survey prepared by Mirucki (1999a), equally exploratory, gave a preliminary picture of the state of economics research in Ukraine.

3. In the United States, this basic knowledge check, which takes place before a jury (PhD Comprehensive Exam), is a precondition of enrolment to the thesis preparation stage, which has the effect of automatically excluding from teaching, even during the probationary period, all candidates who are unable to meet the standard.

4. André Chervel (1993), Histoire de l'agrégation, Paris, Institut National de Recherches Pédagogiques, Editions Kimé.

5. In France, the agrégation competitive economics examination takes place in three stages: discussion of works produced to determine preliminary approval, presentation of a theoretical lesson to confirm approval and a final stage (one or two applied lessons) to establish a classification list of successful candidates.

6. In his report as President of the Jury of the 1995-1996 agrégation examination, Bourguinat (1997) goes even further: "... the Jury, breaking somewhat with tradition, having decided to reject certain candidates who, albeit of a fair standard, might not have succeeded in completing the examination process" (p. 132). Candidates eliminated in this way then have to accept a negative judgement on their research work and will not be given a chance to try to improve their performance in the lessons, in the event that they might sit the examination again, nor are they left the choice of voluntarily withdrawing their candidature between two tests to avoid the humiliation of a rejection, which is candidly admitted to be unfair but which nevertheless officially amounts to a clear-cut failure.

7. Several authors have tackled the issue of the characteristics of the French university system, such as Frey and Eichenberger (1993), Kolm (1988), Portes (1987), Ratier-Coutrot (1985) and Wolfelsperger, Pommerehne and Frey (1988).

8. It might be feasible to analyse the case of directors of theses or establishments according to their classification ranking or the degree of success achieved by their approved candidates.

9. Maurice Allais, winner of the Nobel Prize for Economics in 1988, did in fact go through the previous two appointments, his initial membership of the Fellows in 1949 being followed by his confirmation as Foreign Honorary Member of the American Economic Association in 1976.

10. Out of the ten members of the EconLit 100+ group, four are academics and three teach in the provinces. It is significant to note that all four completed part of their studies and/ or career abroad. 
11. For reasons of editorial convenience, only three of the 19 graphs produced have been included in this article, but readers who are interested may obtain the missing details from the author.

12. Traditionally, the Jury presidents of agrégation examinations are appointed from among the professors on the highest "rungs" of the ladder, in other words, at the highest grade and step of all teacher-researchers in each discipline, with an alternation between Paris and provincial universities. This hierarchical position is itself determined in the light of promotion decisions taken during the individuals' careers by the CNU. Hence the fact that the functional links between the $\mathrm{CNU}$ and the agrégation examination clearly illustrate the notion of "French specificity".

13. In recent years, the number of journals covered by EconLit has doubled, by now exceeding 600, the great majority of which are English-language publications.

14. Out of a total of 15 prize-winners, the only exception was Leonid Kantorovitch (USSR) in 1975.

15. Although the anonymity rule was applied to all groups, it is clear that merely by comparing different memberships, it is quite easy to identify the person in question, who is none other than Jean-Jacques Laffont, Professor at Toulouse I University. 


\section{References}

BAIRAM, E.I. (1994), "Institutional affiliations of contributors to top economic journals, 1985-1990", Journal of Economic Literature, Vol. 32, pp. 674-679.

BLANK, R.M. (1991), "The effects of double-blind versus single-blind reviewing: experimental evidence", American Economic Review, Vol. 81, pp. 1041-1067.

BOURGUINAT, H. (1997),

“Rapport sur le concours d'agrégation de sciences économiques 1995-1996", Revue d'Économie Politique, Vol. 107, pp. 131-140.

CHERVEL, A. (1993), Histoire de l'agrégation, Institut national de recherches pédagogiques, Éditions Kimé, Paris.

CHUNG, K.H., COX, R.A.K. and OKUNADE, A.A. (1993), "Publishing behavior of individuals and most prolific authors in the economics literature", Quarterly Journal of Business and Economics, Vol. 32, pp. 32-42.

COLANDER, D. (1989),

"Research on the economics profession", Journal of Economic Perspectives, Vol. 3, pp. 137-148.

CONROY, M.E. et al. (1995),

"The productivity of economics departments in the US: Publications in the core journals", Journal of Economic Literature, Vol. 33, pp. 1966-1971.

DAVIS, P. and PAPANEK, G. (1984),

"Faculty rating of major economics departments by citations", American Economic Review, Vol. 74, pp. 225-229.

DELORME, C.D. and KAMERSCHEN, D.R. (1987),

"What 'Who's Who in Economics' tells us about the economics profession", Quarterly Review of Economics and Business, Vol. 37, pp. 65-79.

DOWNING, P.B. and STAFFORD, E.A. (1981), "Citations as an indicator of classic works and major contributors in social science", Public Choice, Vol. 37, pp. 219-230.

EHRENBERG, R.G. (coordinated by) (1997),

The American University: National Treasure or Endangered Species? Cornell University Press, Ithaca.

FREY, B.S. and EICHENBERGER, R. (1993),

"American and European economics and economists", Journal of Economic Perspectives, Vol. 7, p. 185-193. 
GANS, J.S. and SHEPHERD, G.B. (1994),

"How are the mighty fallen: rejected classic articles by leading economists", Journal of Economic Perspectives, Vol. 8, pp. 165-179.

GOODWIN, T.H. and SAUER, R.D. (1995),

"Life cycle productivity in academic research: evidence from cumulative publication histories of academic economists", Southern Economic Journal, Vol. 61, pp. 728-743.

HAMERMESH, D.S. (1994),

"Facts and myths about refereeing", Journal of Economic Perspectives, Vol. 8, pp. 153-163.

HANSEN, W.L. (1991),

"The education and training of economics doctorates", Journal of Economic Literature, Vol. 29, pp. 1054-1087.

HICKS, D. (1999),

"The difficulty of achieving full coverage of international social science literature and the bibliometric consequences", Scientometrics, Vol. 44, pp. 193-217.

HODGSON, G.M. and ROTHMAN, H. (1999),

"The editors and authors of economics journals: a case of institutional oligopoly?", Economic Journal, Vol. 109, pp. 165-186.

KASPER, H. et al. (1991),

"The education of economists", Journal of Economic Literature, Vol. 29, pp. 1088-1 109.

KOLM, S.C. (1988),

"Economics in Europe and the US.", European Economic Review, Vol. 32, pp. 207-212.

LABAND, D.N. (1990),

"Measuring the relative impact of economics book publishers and economics journals", Journal of Economic Literature, Vol. 28, pp. 655-660.

LABAND, D.N. and PIETTE, M.J. (1994),

"The relative impacts of economics journals: 1970-1990", Journal of Economic Literature, Vol. 30, pp. 640-666.

LAFFONT, J.J. (1995),

“Réflexions sur l'agrégation d'économie”, Revue d'Économie Politique, Vol. 105, pp. 353-356.

LIEBOWITZ, S.J. and PALMER, J.P. (1984),

"Assessing the Relative Impacts of Economics Journals", Journal of Economic Literature, Vol. 22, pp. 77-88.

LOVELL, M.C. (1973),

"The Production of Economic Literature: An Interpretation", Journal of Economic Literature, Vol. 11, pp. 27-55.

MCPHERSON, M.S. and SCHAPIRO, M.O. (1999),

“Tenure Issues in Higher Education", Journal of Economic Perspectives, Vol. 13, pp. 85-98.

MIRUCKI, J. (1986),

"Prix Nobel: les lauréats prennent de l'âge", Collection: Des idées, des événements, Le Devoir, 21 octobre 1986.

MIRUCKI, J. (1999a),

"A Visibility Analysis of the Scientific Production of Ukrainian Economists: 1969-94",

$102 \quad$ Journal of Socio-Economics, Vol. 28, pp. 221-232. 
MIRUCKI, J. (19996),

"What does an American Economic Association Foreign Honorary Membership Nomination Really Imply?", working paper.

NEDERHOF, A.J. and WIJK, E. (1999),

"Profiling Institutes: Identifying High Research Performance and Social Relevance in the Social and Behavioral Sciences", Scientometrics, Vol. 44, pp. 487-506.

PORTES, R. (1987),

"Economics in Europe”, European Economic Review, Vol. 31, pp. 1329-1340.

RATIER-COUTROT, L. (1985),

"Les économistes français vus d'Amérique", Futuribles, Vol. 91, pp. 71-76.

WOLFELSPERGER, A., POMMEREHNE, W.W. and FREY, B.S. (1988),

"La valeur des économistes français", Revue française d'économie, Vol. 3, pp. 145-174.

WOUTERS, P. (1999),

"Beyond the Holy Grail: from citation theory to indicator theories", Scientometrics, Vol. 44, pp. $561-580$ 